\title{
Clinical and serological follow-up of patients with WDEIA
}

\author{
Morten J. Christensen ${ }^{1 *}\left(\mathbb{D}\right.$, Esben Eller ${ }^{1}$, Charlotte G. Mortz ${ }^{1}$, Knut Brockow ${ }^{1,2}$ and Carsten Bindslev-Jensen ${ }^{1}$
}

\begin{abstract}
The clinical threshold in wheat-dependent, exercise-induced anaphylaxis seems to be lowered in patients on wheat free diet, whereas the opposite is seen in patients on regular wheat intake. Therefore, a recommendation of wheat consumption, if considered safe to the patient based on case-history and challenge results, could be advised.
\end{abstract}

Keywords: Anaphylaxis, Wheat dependent exercise induced anaphylaxis, Gluten, oral food challenge, Exercise challenge, Specific IgE, Specific lgG, Avoidance

To the Editor,

The current recommendations in managing food allergy focuses on avoidance of the offending allergen(s) and use of rescue medication in the event of an allergic reaction [1]. Induction of oral tolerance or desensitization is a potential preventive approach and small amounts of the allergenic food may induce faster tolerance, although the underlying immunological mechanism is incompletely understood [2-4].

Wheat-dependent, exercise-induced anaphylaxis (WDEIA) is a severe variant of food allergy caused by physical exercise or incompletely other co-factors in combination with ingestion of a food containing wheat $[5,6]$. Based on case-history and challenge results patients are recommended either total wheat avoidance or to avoid exercise $4 \mathrm{~h}$ before and after wheat ingestion [7], since the underlying pathophysiological mechanisms of WDEIA are still incompletely understood [8].

The aims of this study were to evaluate the threshold and the immunoglobulin levels in two groups of patients with challenge confirmed WDEIA prescribed either total wheat avoidance or avoidance only in connection to physical exercise. We investigated 12 patients with WDEIA divided in two groups; total wheat avoidance

*Correspondence: morten.junker.christensen@rsyd.dk

${ }^{1}$ Department of Dermatology and Allergy Centre, Odense Research Center for Anaphylaxis (ORCA), Odense University Hospital, 5000 Odense C, Denmark

Full list of author information is available at the end of the article $(\mathrm{n}=5)$ and wheat consumption unless $4 \mathrm{~h}$ before or after exercise $(n=7)$, and conducted two titrated gluten challenges in combination with treadmill exercise 4 weeks apart during this time interval [5]. Skin prick test (SPT) with wheat and gluten together with measurement of specific-IgE (sIgE), sIgG and $\operatorname{sIgG}_{4}$ in serum to wheat and omega-5 gliadin using ImmunoCap (ThermoFisher Scientific, Uppsala, Sweden) were performed at the 1st and 2nd challenge and 4 weeks hereafter, respectively.

We used the statistical software program STATA ${ }^{\circledR}$ version 15.0 (StataCorp LLC, College Station, Texas, USA) and applied the Wilcoxon signed ranks test for the intragroup analysis and Mann-Whitney tests for betweengroup analysis in the absolute change in threshold. Statistical significance was defined as a p value of less than 0.05 . The study was approved by The Regional Committees on Health Research Ethics for Southern Denmark (Project ID: 20140012).

Among the 12 patients included, 8 were previously diagnosed by oral food challenge (OFC) with gluten \pm exercise and for the remaining 4 patients they had their diagnostic challenge performed as part of the 1 st challenge. At time of diagnosis different individual recommendations concerning gluten avoidance were applied corresponding to case-history and challenge results. The median time from the diagnostic challenge to the 1 st challenge was 364 days (range $0-944$ days). No significant change in the gluten threshold eliciting a reaction between the initial challenge and the 1st challenge was found $(\mathrm{p}=0.44)$. There was no difference in clinical 


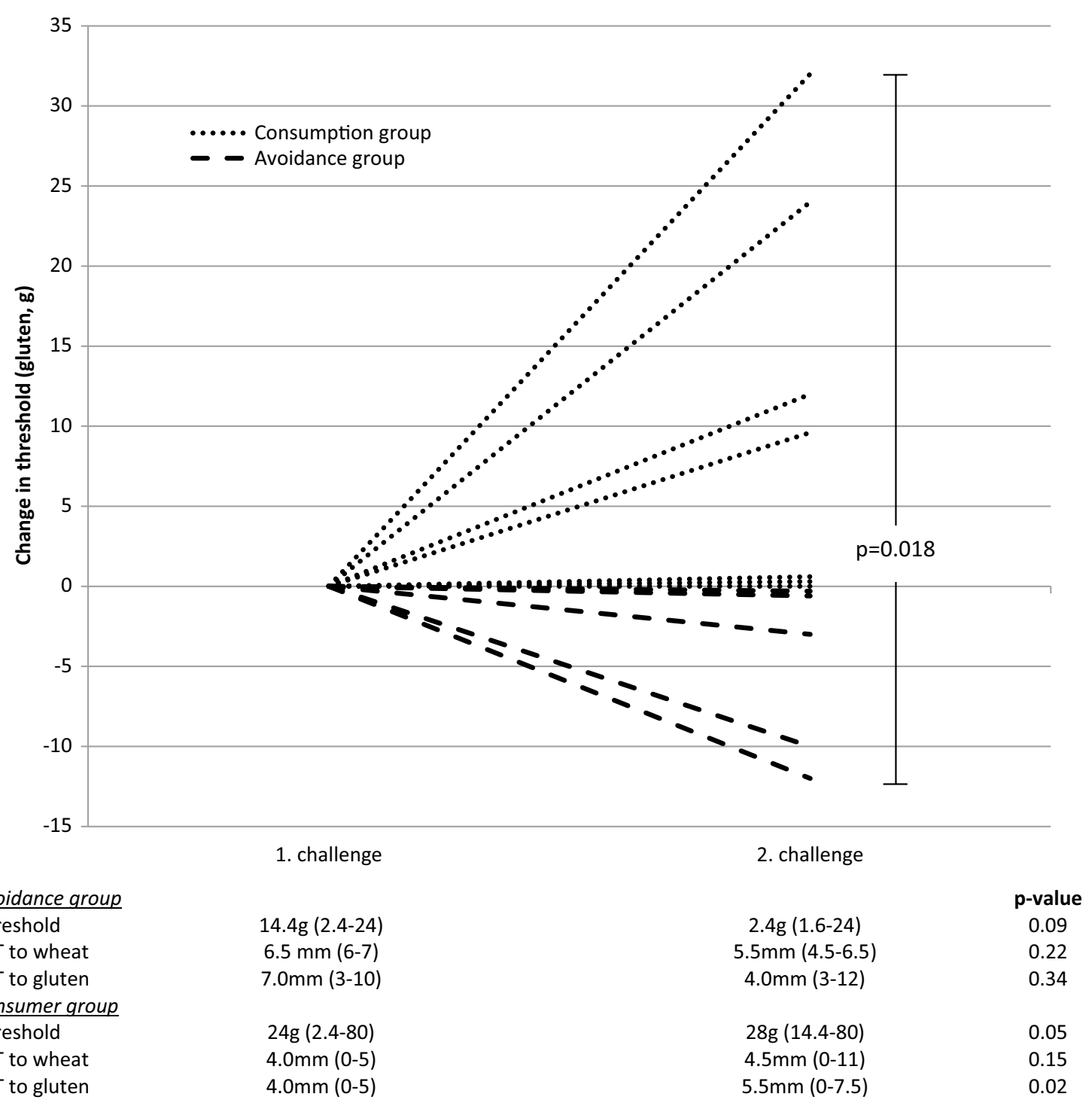

Fig. 1 Change in threshold from 1st to 2 nd challenge in groups of wheat avoidance and consumption. In the wheat avoidance group ( $n=2)$ and the wheat consumption group $(n=3)$ had an unchanged clinical threshold between the 1 st and 2 nd challenge. Values of threshold and SPT are given as medians

reactivity at rest between the two groups; in the total avoidance group $4 / 5$ reacted with a median threshold of $25 \mathrm{~g}$ [8-80 g] compared to $5 / 7$ in the consumption group with a median threshold of $58 \mathrm{~g}[24-80 \mathrm{~g}]$. No reaction at rest was elicited at a maximum amount of $80 \mathrm{~g}$ of gluten in the avoidance group $(\mathrm{n}=1)$ and consumption group $(\mathrm{n}=2)$.

In the avoidance group ( 1 female and 4 male; mean age 51.8 years) the time interval between 1 st and 2 nd challenge was $35 \pm 11$ days and in $60 \%$ (3/5, 2 unchanged) a decrease of the threshold dose was observed with a median decrease of $3.2 \mathrm{~g}[0-12 \mathrm{~g}](\mathrm{p}=0.09)$. In the consumption group ( 3 female and 4 male; mean age 50.7 years) the time interval between the challenges was 28 days \pm 3 and the threshold dose increased in $71 \%(5 / 7$, 2 unchanged) with a median increase of $9.6 \mathrm{~g}[0-32 \mathrm{~g}]$ $(\mathrm{p}=0.05)$ (see Fig. 1). A significant difference was observed $(\mathrm{p}=0.018)$ in the absolute change in thresholds between the avoidance group and the consumption group from the 1st to the 2nd challenge (see Fig. 1).

Levels of sIgE, sIgG and $\operatorname{sIgG}_{4}$ to wheat and omega- 5 gliadin in serum were measured at 1 st and 2 nd challenge as well as 4 weeks hereafter. There were no significant differences between groups or changes over time, neither 
for immunoglobulin levels, nor for the ratio of wheat or omega- 5 gliadin $\operatorname{sIgG}_{4}$ :IgE in any of the groups (see Additional file 1: Table S1). Wheal size with wheat and gluten did not change over the period between 1st and 2nd challenge (see Fig. 1).

Wheat is a source of food widely used in the daily household and this is to the author's knowledge the first study comparing the clinical effects and immunological responses to groups with wheat avoidance and consumption in WDEIA. Although only patients with severe reactions and low thresholds were actively prescribed total avoidance, some patients autonomously chose total wheat avoidance for convenience. There is therefore no active randomization applied to the patients. There were no significant difference in rates of hospitalization, serious adverse events or exercise frequency/intensity between the avoidance group and the consumption group during study period.

The main finding is that patients with doctor guided total avoidance developed a decrease in threshold and those on regular wheat intake outside $4 \mathrm{~h}$ before or after exercise had an increase in threshold levels, which was not reflected by skin test and immunoglobulin parameters. Therefore, regular intake of wheat not related to exercise may be superior as compared to total avoidance for building up higher threshold levels and may be recommended. This could be similar to oral immunotherapy in children with wheat allergy. Results have shown successful development of tolerance accompanied by increased levels of $\operatorname{sIgG}_{4}$ and decreased levels IgE to wheat, 6 months after an up-dosing regimen [9]. Surprisingly, an expected increase in levels of $\operatorname{sIgG}_{4}$ or sIgG elicited by challenge was not seen in any of the two groups, nor was the level of sIgG in serum higher in the consumption group compared to the avoidance group, in contrast to regular successful immunotherapy, where an increase in $\operatorname{sgG}$ and $\operatorname{IgG}_{4}$ is seen [10]. This may be related to the lack of high allergen doses given during immunotherapy and to the short duration of the study of only 2 months.

A weakness to this study is a relatively small study size of 12 patients with a lack of a blinded randomized regimen and that in both groups before the 1st challenge, either wheat avoidance or wheat consumption was allowed. Furthermore additional dose-titration-steps of gluten (maximum 4 steps) could have been applied in other to determine and demonstrate a wider change in threshold in the respective groups.

In conclusion, the clinical threshold in WDEIA seems to be lowered in patients on wheat-free diet, whereas the opposite is seen in patients on regular wheat intake. Therefore, a recommendation of wheat consumption, if considered safe to the patient based on case-history and challenge results, could be chosen. Further investigations and larger investigations are however needed to support these findings.

\section{Additional file}

Additional file 1: Table S1. Levels of slgE, slgG and $\operatorname{slgG}_{4}$ to wheat and omega- 5 gliadin in groups of wheat avoidance and consumption in WDEIA. ${ }^{*} 1$ patient and 2 patients in the wheat avoidance group and the wheat consumption group, respectively, did not have a blood sample drawn 4 weeks after the 2 nd challenge.

\section{Abbreviations}

slgE: specific immunoglobulin E; OFC: oral food challenge; SPT: skin prick test; WDEIA: wheat-dependent exercise-induced anaphylaxis.

\section{Acknowledgements}

None.

\section{Authors' contributions}

MJC has evaluated the patients and performed the data analysis and drafted the manuscript. All co-authors (EE, CGM, KB and CBJ) have contributed to conception and design of the study and interpretation and discussion of the results. All authors read and approved the final manuscript.

\section{Funding}

None.

Availability of data and materials

Authors can confirm that all relevant data are included in the article and/or its supplementary information files.

\section{Ethics approval and consent to participate}

The study was approved by The Regional Committees on Health Research Ethics for Southern Denmark (Project ID:20140012). All participants have made a written consent of participation. Written consent was obtained from all participants for participation and publication.

\section{Consent for publication}

Written consent has been obtained from all participants for publication.

\section{Competing interests}

The authors declare that they have no competing interests.

\section{Author details}

${ }^{1}$ Department of Dermatology and Allergy Centre, Odense Research Center for Anaphylaxis (ORCA), Odense University Hospital, 5000 Odense C, Denmark. ${ }^{2}$ Department of Dermatology and Allergy Biederstein, Technische Universität München, Munich, Germany.

Received: 31 January 2019 Accepted: 14 May 2019

Published online: 16 May 2019

\section{References}

1. Muraro A, Werfel T, Hoffmann-Sommergruber K, Roberts G, Beyer K, Bindslev-Jensen C, et al. EAACI food allergy and anaphylaxis guidelines: diagnosis and management of food allergy. Allergy. 2014;69(8):1008-25.

2. Pajno GB, Fernandez-Rivas M, Arasi S, Roberts G, Akdis CA, Alvaro-Lozano $M$, et al. EAACI Guidelines on allergen immunotherapy: IgE-mediated food allergy. Allergy. 2018;73(4):799-815.

3. Upton J, Nowak-Wegrzyn A. The impact of baked egg and baked milk diets on IgE- and non-IgE-mediated allergy. Clin Rev Allergy Immunol. 2018;55(2):118-38. 
4. Esmaeilzadeh $\mathrm{H}$, Alyasin S, Haghighat M, Nabavizadeh $\mathrm{H}$, Esmaeilzadeh E, Mosavat F. The effect of baked milk on accelerating unheated cow's milk tolerance: a control randomized clinical trial. Pediatr Allergy Immunol. 2018;29(7):747-53.

5. Scherf KA, Brockow K, Biedermann T, Koehler P, Wieser H. Wheat-dependent exercise-induced anaphylaxis. Clin Exp Allergy. 2016;46(1):10-20.

6. Christensen MJ, Eller E, Mortz CG, Brockow K, Bindslev-Jensen C. Wheatdependent cofactor-augmented anaphylaxis: a prospective study of exercise, aspirin, and alcohol efficacy as cofactors. J Allergy Clin Immunol In Pract. 2019;7(1):114-21.

7. Christensen MJ, Eller E, Mortz CG, Brockow K, Bindslev-Jensen C. Exercise lowers threshold and increases severity, but wheat-dependent, exerciseinduced anaphylaxis can be elicited at rest. J Allergy Clin Immunol In Pract. 2018;6(2):514-20.

8. Ansley L, Bonini M, Delgado L, Del Giacco S, Du Toit G, Khaitov M, et al. Pathophysiological mechanisms of exercise-induced anaphylaxis: an EAACI position statement. Allergy. 2015;70(10):1212-21.
9. Rodriguez del Rio P, Diaz-Perales A, Sanchez-Garcia S, Escudero C, do-Santos P, Catarino M, et al. Oral immunotherapy in children with IgE-mediated wheat allergy: outcome and molecular changes. J Investig Allergol Clin Immunol. 2014;24(4):240-8.

10. Nouri-Aria KT, Wachholz PA, Francis JN, Jacobson MR, Walker SM, Wilcock LK, et al. Grass pollen immunotherapy induces mucosal and peripheral IL-10 responses and blocking IgG activity. J Immunol (Baltimore, Md: 1950). 2004;172(5):3252-9.

\section{Publisher's Note}

Springer Nature remains neutral with regard to jurisdictional claims in published maps and institutional affiliations.
Ready to submit your research? Choose BMC and benefit from:

- fast, convenient online submission

- thorough peer review by experienced researchers in your field

- rapid publication on acceptance

- support for research data, including large and complex data types

- gold Open Access which fosters wider collaboration and increased citations

- maximum visibility for your research: over $100 \mathrm{M}$ website views per year

At BMC, research is always in progress.

Learn more biomedcentral.com/submissions 